\title{
Improving the quality of peak flow measurements for the diagnosis of occupational asthma
}

\author{
Vicky Huggins ${ }^{1}$, Wasif Anees ${ }^{1}$, Charles Pantin ${ }^{2}$ and Sherwood Burge ${ }^{1}$
}

Introduction Serial measurements of peak expiratory flow (PEF) are recommended in the evidence-based review list as the first stage in objective confirmation of occupational asthma. Different centres have reported widely different success in obtaining records of sufficient data quantity for diagnosis. We investigated different methods of instruction and determined the return rate and quality of the resulting record for the diagnosis of occupational asthma.

Methods Consecutive new referrals were recruited from a specialized occupational lung disease clinic and requested to carry out serial PEFs for the assessment of suspected occupational asthma. Requests to carry out the records were either from written postal instructions or personal instruction from a PEF specialist. Record quality received from other clinicians was also analysed separating those using dedicated occupational forms, and those submitting on graph type forms.

Results $\quad$ The postal return rate was $56 \%$ and the personal rate $85 \%$. The number of records fulfilling all the data quality criteria were similar in the postal and personal groups (55 and 59\%, respectively). Pre-existing records from other clinics plotted from graph charts (fulfilling all criteria) were only adequate in $23 \%$, compared with $61 \%$ adequate for pre-existing records plotted from occupational forms. Failure of the record to contain consecutive work periods of $\geq 3$ workdays was the most common failure.

Conclusion The return rate of PEFs for diagnosing occupational asthma is better when patients have been given specific instructions from a PEF specialist and the data quantity better when recorded on a dedicated form.

Key words Diagnosis; occupational asthma; peak expiratory flow measurements.

\section{Introduction}

Serial measurements of peak expiratory flow (PEF) are recommended as the first objective confirmatory test in workers with suspected occupational asthma [1]. Previous work has shown computer-assisted analysis of serial PEF records to have a sensitivity of $73-86 \%$ and a specificity of $74-100 \%$ [2-4]. The ability to obtain records of diagnostic value varies considerably with success rates of $52 \%$ in laboratory animal workers, $54 \%$ in previously diagnosed workers, $62 \%$ in grain workers, $63 \%$ in autobody shop workers, $78 \%$ of workers given an electronic peak flow meter and $78 \%$ of electroplaters [5-10]. Most of these studies achieved these results by visiting workers and/or seeing them in clinic. As records are quite labour intensive, it requires a certain degree of motivation and dedication from the patient, which is why return rates and data quantity can be low. However, there

\footnotetext{
${ }^{1}$ Birmingham Heartlands Hospital, Respiratory Medicine, Bordesley Green East, Birmingham B9 5SS, UK.

${ }^{2}$ City General Hospital, Newcastle Road, Stoke-on-Trent, Staffs ST4 6QG, UK

Correspondence to: Vicky Huggins, Birmingham Heartlands Hospital, Respiratory Medicine, Bordesley Green East, Birmingham B9 5SS, UK. Tel: +44 121424 2745; fax: +441217720292.

e-mail: Vicky.Huggins@heartsol.wmids.nhs.uk
}

is also the problem of workers fabricating data and several studies have found that when logging meters are used, only approximately $55 \%$ of the data is completely accurate $[7,11]$. We have also studied this previously and found that workers often regress to the mean peak flow value rather than giving themselves occupational asthma when fabricating records and the meters themselves can sometimes be the cause of inaccuracies [12]. As it is not currently known how many people can return adequate quality records when instructed on paper only, or whether the type of charts given to record the results on affects the quality of the data sent back, we undertook this study comparing three different ways of obtaining PEF records for the assessment of occupational asthma. We evaluated how many records were returned and how many fulfilled all data quality criteria (using pre-defined criteria) for the diagnosis of occupational asthma.

\section{Methods}

Three ways of obtaining PEF charts were investigated:

1. Postal. Upon receipt of a referral letter consecutive patients with suspected occupational asthma were sent 
written instructions from a PEF specialist and specialized forms prior to being seen in clinic.

2. Personal. Patients seen consecutively in the Occupational Lung Disease Clinic where further evidence of suspected occupational asthma was required were given charts and verbal instructions by a PEF specialist at their clinic appointment.

3. Other records. Consecutive peak flow records forwarded to us from patients seen and instructed in either a primary care or hospital clinic or by their employer's occupational health department were also analysed.

It is not known what instructions were given to this group. Each subject in both the personally instructed and the postal groups was given dedicated occupational record forms (see Figure 1, available as Supplementary data at Occupational Medicine Online) and asked to record the best of three readings every $2 \mathrm{~h}$ from waking until going to bed, at and away from work for a total of 4 weeks (see Figure 2, available as Supplementary data). The other records group generally used either graph charts such as those enclosed with the mini-Wright peak flow meter or forms that imitated our occupational record forms.

All records were plotted using Oasys-2 (Occupational Asthma System), which is a program specifically designed to analyse serial peak flow measurements using discriminant analysis [13]. The program scores the results from 1 to 4 on the probability of the record showing occupational asthma. To create the scores, Oasys analyses complexes that can be made up of either a rest-work-rest period (1 complex) or a work-rest-work period ( $1 \mathrm{com}-$ plex). The records received in this study were assessed for data quantity using pre-defined criteria which gave optimal sensitivity and specificity for Oasys analysis. These have been defined as: ( 1$) \geq 4$ readings per day, (2) $\geq 3$ complexes in duration (equivalent to $2.5-3$ standard working weeks) and (3) at least 3 consecutive workdays in the majority of work periods in the record [14].

The $\chi^{2}$-test was used to compare postal instruction versus personal instruction versus instructed by other (occupational forms) to see whether there was a significant difference in the data quantity received back. It was also used to compare all data received on occupational forms to that received on graph forms. The Yates' continuity correction was used for the latter group.

\section{Results}

Results are presented for 158 consecutive workers sent postal instructions and 86 instructed personally. The mean age of the postal group was $46(22-74)$ and of the personal group $46(21-63)$ and there were $69 \%$ males and $31 \%$ females in the postal group, 59\% males and
$41 \%$ females in the personal group (the instruction by other group is not known). A range of occupations were included such as foundry workers, welders, health care workers and school teachers. The return rates following postal and personal instruction were 56 and $85 \%$, respectively $\left(P<0.001, \chi^{2}\right.$-test $)$. We were unable to calculate the return rate for the other records group as we had no denominator data for this group. Table 1 shows the quality of returned records for the diagnosis of occupational asthma. Of the records returned, 16 postal records, five personal records and nine instructed by other records had no periods at work. No further data from these are presented. The quality was similar for all using specialized occupational forms $(P>0.104$ for all criteria tested using the $\chi^{2}$-test), and significantly better than those not using them $(P<0.05$ for all criteria except duration of the record where $P=0.16, \chi^{2}$-test). Completing at least four readings per day was the most easily achieved element. Working for at least 3 consecutive days was the factor most likely to lead to an inadequate record quality.

Table 2 shows the inclusion of other information required to analyse the record for work effect, such as times at work and treatment changes, which is important for analysis with Oasys-2. Details of times of waking and work exposure and changes in treatment were recorded significantly more often when specialized occupational forms were used $(P<0.001)$, but were not different between those instructed personally, by post or by others $(P>0.14)$.

\section{Discussion}

Our study found that personal instruction in completing serial PEF measurements increased the proportion of patients returning records to $85 \%$ compared with $56 \%$ for those receiving written instructions. Fifty-nine per cent of those personally instructed were able to return a record fulfilling all data quality criteria. The commonest reason for poor quality records from the point of view of the diagnosis of occupational asthma was the requirement for at least 3 consecutive days at work for $>75 \%$ of work weeks, which reduces record sensitivity but does not affect specificity [13]. This limitation was due to most workers having little say in their work pattern and this factor was beyond their control. Records with less than 3 complexes (approximately 3 work weeks) compromise specificity, but short duration of recording was an infrequent problem when specifically instructed to keep a 4-week record. The number of readings a day influences the assessment of diurnal variation, and particularly helps in records with different shifts, but, in this study at least, four readings/day was the most easily achieved factor. Overall, the amount of data quantity depended mainly on 
Table 1. Summary of results of number of patients who returned adequate quality PEFs for each group

\begin{tabular}{|c|c|c|c|c|c|c|c|c|}
\hline & $\begin{array}{l}\text { Postal } \\
(n=158)\end{array}$ & $\begin{array}{l}\text { Personal } \\
(n=86)\end{array}$ & $\begin{array}{l}\text { Other } \\
\text { (occupational } \\
\text { forms) }\end{array}$ & $\begin{array}{l}\text { Other } \\
\text { (graph } \\
\text { forms) }\end{array}$ & $\begin{array}{l}\chi^{2} \text { (method } \\
\text { of instruction) }\end{array}$ & $P$ & $\begin{array}{l}\chi^{2} \\
\text { (occupational } \\
\text { versus graph } \\
\text { forms) }\end{array}$ & $P$ \\
\hline $\begin{array}{l}\text { No. of PEFs analysed (those not } \\
\text { at work not included) (no.) }\end{array}$ & $72(16)$ & $68(5)$ & $18(2)$ & $13(7)$ & N/A & N/A & N/A & N/A \\
\hline $\begin{array}{l}\text { Adequate duration ( } \geq 3 \text { complexes) } \\
(\%)\end{array}$ & 80 & 79 & 100 & 62 & 4.54 & 0.10 & 1.96 & 0.16 \\
\hline $\begin{array}{l}\geq 3 \text { consecutive workdays in most } \\
\text { work periods (\%) }\end{array}$ & 73 & 72 & 66 & 31 & 0.26 & 0.88 & 7.54 & $<0.01$ \\
\hline$\geq 4$ readings per day $(\%)$ & 93 & 91 & 94 & 39 & 0.31 & 0.86 & 29.04 & $<0.0001$ \\
\hline Adequate for all criteria (\%) & 55 & 59 & 61 & 23 & 0.36 & 0.84 & 4.36 & $<0.05$ \\
\hline $\begin{array}{l}\text { Factors within workers control: } \geq 3 \\
\text { complexes and } \geq 4 \text { readings } \\
\text { per day only }(\%)\end{array}$ & 75 & 77 & 94 & 39 & 3.18 & 0.20 & 8.02 & $<0.01$ \\
\hline $\begin{array}{l}\% \text { of PEFs adequate for all quality } \\
\text { criteria and work/rest times }\end{array}$ & 51 & 54 & 56 & 8 & 0.26 & 0.88 & 8.07 & $<0.01$ \\
\hline $\begin{array}{l}\% \text { of PEFs adequate for factors } \\
\text { within workers control: } \geq 3 \\
\text { complexes, } \geq 4 \text { readings per day } \\
\text { and work/rest times }\end{array}$ & 71 & 72 & 83 & 15 & 1.12 & 0.57 & 15.92 & $<0.0001$ \\
\hline
\end{tabular}

Table 2. Percentage of PEFs containing additional information

\begin{tabular}{|c|c|c|c|c|c|c|c|c|}
\hline$\%$ recorded & Postal & Personal & $\begin{array}{l}\text { Other } \\
\text { (occupational } \\
\text { forms) }\end{array}$ & $\begin{array}{l}\text { Other } \\
\text { (graph } \\
\text { forms) }\end{array}$ & $\begin{array}{l}\chi^{2} \text { (method } \\
\text { of instruction) }\end{array}$ & $P$ & $\begin{array}{l}\chi^{2} \text { (occupational } \\
\text { versus graph } \\
\text { forms) }\end{array}$ & $P$ \\
\hline $\begin{array}{l}\text { No. of PEFs analysed for } \\
\text { non-work related criteria }\end{array}$ & 89 & 73 & 20 & 20 & N/A & $\mathrm{N} / \mathrm{A}$ & $\mathrm{N} / \mathrm{A}$ & $\mathrm{N} / \mathrm{A}$ \\
\hline Work/rest times & 88 & 92 & 89 & 15 & 0.74 & 0.69 & 63.40 & $<0.0001$ \\
\hline Treatment & 72 & 63 & 50 & 25 & 3.95 & 0.14 & 11.12 & $<0.001$ \\
\hline All additional information & 57 & 51 & 44 & 5 & 1.33 & 0.52 & 14.95 & $<0.0001$ \\
\hline
\end{tabular}

the record form used, rather than the method of instruction. The main reason for not returning the personally instructed records was failing to keep the next clinic appointment because postal records were being lost in the post and a small number of workers were found to be illiterate.

Our written instructions ask for 2-hourly readings from waking to going to bed. We have previously shown that satisfactory sensitivity and specificity can be obtained with at least four daily readings, which were the quality standard used in this study [13]. These criteria were more stringent than many other studies that have requested peak expiratory flows to aid diagnosis of occupational asthma. For example, Henneberger et al. [9] managed to obtain $54 \%$ of records when requesting 15 days of readings. However, it was commented that if readings had been obtained when conditions were first diagnosed, they may have been more successful.
This may also be true for our study as some had already changed exposure when peak flows were requested. A similar scenario was found in a group of laboratory animal workers by Hollander et al. [5], where 208 out of $398(52 \%)$ managed to supply at least 9 days of readings containing information at and away from work. Others who have achieved better return rates and data quality in defined populations include Gannon et al. [10], who attempted to obtain records in an entire cohort of electroplaters and received satisfactory records from $78 \%$ of workers after two visits. Blainey et al. [6] studied 133 grain dockers and farmers by seeing them in clinic and giving them a mini-Wright peak flow meter with a set of written instructions and obtained recordings from $62 \%$ of this epidemiologically defined cohort. Cullen et al. [8] found that, out of 38 autobody shop workers given full training on how to take peak flow readings, only $24(63 \%)$ provided adequate data. 
Although fabrication of readings could be a factor in this study, previous studies have found that $71-79 \%$ of recorded values were stored on the meter even though the time and reading may have differed slightly $[7,11]$ and, as we are examining across groups, one group is no more likely to fabricate than another, so this is unlikely to be an important factor in this study.

We have shown that return rates can be significantly increased by personally instructing patients in clinic. Being adaptable with timing may also have improved this. For example, those unable to leave their workplace or those wearing respiratory protective equipment make readings on waking, arriving at work, at each break, on leaving work, mid-evening and bedtime, overcoming rigid timing problems. We have also shown the importance of using a dedicated form when completing serial peak flows by comparing those plotted on a graph chart to those on an occupational form (instructions on peak flow completion and record forms can be downloaded from www.occupationalasthma.com). Further research regarding the reproducibility of peak flow charts could be undertaken to see whether adequate quality and return rates can be maintained.

\section{References}

1. British Occupational Health Research Foundation. Occupational Asthma: Identification, Management and Prevention: Evidence Based Review and Guidelines. www.bohrf. org.uk/content/asthma.htm

2. Perrin B, Lagier F, L'Archeveque J, et al. Occupational asthma: validity of monitoring of peak expiratory flow rates and non-allergic bronchial responsiveness as compared to specific inhalation challenge. Eur Respir F 1992;5:40-48.

3. Cote J, Kennedy S, Chan-Yeung M. Sensitivity and specificity of PC20 and peak expiratory flow in cedar asthma. F Allergy Clin Immunol 1990;85:892-898.
4. Leroyer C, Perfetti L, Trudeau C, L'Archeveque J, ChanYeung M, Malo JL. Comparison of serial peak expiratory flow and FEV1 in the diagnosis of occupational asthma. Am F Respir Crit Care Med 1998;158:827-832.

5. Hollander A, Heederik D, Brunekreef B. Work related changes in peak expiratory flow among animal workers. Eur Respir F 1998;11:929-936.

6. Blainey AD, Topping MD, Ollier S, Davies RJ. Allergic respiratory disease in grain workers: the role of storage mites. F Allergy Clin Immunol 1989;84:296-303.

7. Quirce S, Contreras G, Dybuncio A, Chan Yeung M. Peak expiratory flow monitoring is not a reliable method for establishing the diagnosis of occupational asthma. $A m \mathcal{F}$ Respir Crit Care Med 1995;152:1100-1102.

8. Cullen MR, Redlich CA, Beckett WS, et al. Feasibility study of respiratory questionnaire and peak flow recordings in autobody shop workers exposed to isocyanate-containing spray paint: observations and limitations. Occup Med (Lond) 1996;46:197-204.

9. Henneberger PK, Stanbury MJ, Trimbath LS, Kipen HM. The use of portable peak flowmeters in the surveillance of occupational asthma. Chest 1991;100:1515-1521.

10. Gannon PFG, Burge PS. Interpretation of serial peak expiratory flow records from workers in an electroplating factory. Thorax 1993;48:416-417.

11. Malo JL, Trudeau C, Ghezzo H, L'Archeveque J, Cartier A. Do subjects investigated for occupational asthma through serial peak expiratory flow measurements falsify heir results? F Allergy Clin Immunol 1995;96:601-607.

12. Anees W, Huggins V, Burge PS. Reliability of PEF diaries. Thorax 2001;56:742.

13. Anees W, Gannon PF, Huggins V, Pantin CFA, Burge PS. Effect of peak expiratory flow data quantity on diagnostic sensitivity and specificity in occupational asthma. Eur Respir F 2004;23:730-734.

14. Gannon PFG, Newton DT, Belcher J, Pantin CFA, Burge PS. Development of Oasys-2: a system for the analysis of measurement of peak expiratory flow in workers with suspected occupational asthma. Thorax 1996;51:484-489. 